\title{
Christofle Du Pré, Les Larmes funebres
}

\section{Michele Mastroianni}

\section{(2) OpenEdition}

\section{Journals}

\section{Edizione digitale}

URL: http://journals.openedition.org/studifrancesi/35923

DOI: 10.4000/studifrancesi.35923

ISSN: 2427-5856

\section{Editore}

Rosenberg \& Sellier

\section{Edizione cartacea}

Data di pubblicazione: 1 juillet 2005

Paginazione: 148-149

ISSN: 0039-2944

\section{Notizia bibliografica digitale}

Michele Mastroianni, «Christofle Du Pré, Les Larmes funebres», Studi Francesi [Online], 145 (XLIX | I) 2005, online dal 30 novembre 2015, consultato il 18 avril 2021. URL: http://journals.openedition.org/ studifrancesi/35923 ; DOI: https://doi.org/10.4000/studifrancesi.35923

\section{Questo documento è stato generato automaticamente il 18 avril 2021.}

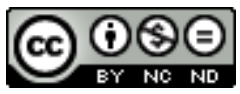

Studi Francesi è distribuita con Licenza Creative Commons Attribuzione - Non commerciale - Non opere derivate 4.0 Internazionale. 


\title{
Christofle Du Pré, Les Larmes funebres
}

\author{
Michele Mastroianni
}

\section{NOTIZIA}

CHRISTOFLE DU PRÉ, Les Larmes funebres, édition critique par PIERRE MARTIN, Genève, Droz («Textes Littéraires Français», 564), 2004, pp. 254.

1 In questi ultimi anni abbiamo assistito, anche grazie alla meritoria collezione ginevrina dei «Textes Littéraires Français», al moltiplicarsi di interessanti riscoperte (con le conseguenti edizioni critiche) di autori e di raccolte poetiche cinquecentesche che non avevano goduto di riedizioni dal XVI secolo. Una delle ultime acquisizioni è il piccolo canzoniere (settantacinque sonetti e tre odi) che nel 1577 Christofle Du Pré, sieur de Passy en Brie, pubblicò, col titolo squisitamente manierista Les Larmes funebres, in memoria e omaggio alla moglie morta. Ancora nel 1990 Jacques Roubaud, in una sua antologia del sonetto francese da Marot a Malherbe (Soleil du Soleil, Paris, Gallimard, «Poésie»), inserendo due sonetti di Du Pré, nelle note biografiche si limitava a dire: «Je ne sais rien de Christofle Du Pré». Ora, Pierre Martin per la sua edizione, nella prima parte di una ricca introduzione (Fragments d'une biographie, pp. 11-43), riesce a raccogliere tutta una serie di notizie sulla famiglia e sull'entourage di questo ignorato autore, soffermandosi soprattutto sul matrimonio, che è all'origine del canzoniere, e su un viaggio-ambasciata a Costantinopoli. Inoltre viene ricostruita la rete di contatti letterari da parte di Du Pré, contatti attestati anche da alcune pièces "estravaganti», che Martin recensisce accuratamente. Nella seconda parte dell'introduzione (Passy passionné, pp. 43-143), abbiamo uno studio sulle Larmes funebres, che vengono viste come connesse soprattutto, sul piano formale, con l'opera ronsardiana e certamente lontane da canzonieri neopetrarchisti contemporanei, e alla moda, quali Le misogame di Jamyn o le stanze di Desportes, la cui caratteristica misogamica è lontanissima dall'esaltazione dell'amor coniugale propria di Du Pré: esaltazione di un amore che assume quasi la colorazione di una passione cristica. La perlustrazione di alcune tematiche, come quella 
della morte, permette di ricostruire i nessi di immaginario con la poesia del secondo Cinquecento. Accurato è l'esame delle forme stilistiche. L'edizione è rigorosa e puntualmente annotata. 